\title{
A sensitivity analysis to study the influence of surface integrity on the microcrack formation in high strength steels under compressive peak loading
}

jairan nafar dastgerdi ${ }^{1}$, Fariborz Sheibanian ${ }^{2}$, Heikki Remes ${ }^{3,3}$, and Hossein Hosseini-Toudeshky ${ }^{4}$

${ }^{1}$ Aalto University School of Engineering

${ }^{2}$ Amirkabir University of Technology Department of Aerospace Engineering

${ }^{3}$ Aalto University

${ }^{4}$ Amirkabir University of Technology

September 17, 2020

\begin{abstract}
This paper provides a further understanding of the peak load effect on the damage mechanics and residual stress relaxation. The comprehensive numerical simulations using the finite element method are applied to take into account simultaneously the effect of the surface roughness and residual stresses on the crack formation in sandblasted S690 high strength steel surface under peak load condition. A ductile fracture criterion is introduced for the prediction of damage initiation and evolution. This study investigates especially the influences of compressive peak load, effective parameters on fracture locus, surface roughness, and residual stress on damage mechanism and the formed crack size. Results indicate that under peak load conditions, surface roughness has a far more important influence on microcrack formation than residual stress. Moreover, it is shown that the effect of peak load range on damage formation and crack size is significantly higher in comparison with the influence of residual stress. It is found the crack size has been developed exponentially with increasing peak load magnitudes.
\end{abstract}

\section{Hosted file}

manuscript_Final_17.9.2020.pdf available at https://authorea.com/users/359768/articles/ 481578-a-sensitivity-analysis-to-study-the-influence-of-surface-integrity-on-themicrocrack-formation-in-high-strength-steels-under-compressive-peak-loading 